\title{
Increased Insulin Sensitivity and Responsiveness of Glucose Metabolism in Adipocytes from Female Versus Male Rats
}

\author{
Michèle Guerre-Millo, Armelle Leturque, Jean Girard, and Marcelle Lavau \\ Groupe de Recherches sur la Physiopathologie de la Nutrition, INSERM U.177, Institut Biomédical des Cordeliers, \\ 15-21 rue de l'Ecole de Médecine, 75270 Paris Cedex 06. France; and Centre de Recherches sur la Nutrition du CNRS, \\ 9 rue Jules Hetzel, 92190 Meudon-Bellevue, France
}

\begin{abstract}
This study was undertaken to examine whether there were sex-associated differences in the action of insulin on glucose metabolism in adipocytes. Insulin binding and the dose-response curves for glucose transport (assessed by measuring the cellassociated radioactivity after 15-s incubation with $50 \mu \mathrm{M}$ [6- ${ }^{14} \mathrm{C}$ glucose) and $\left[\mathrm{U}-{ }^{14} \mathrm{C}\right.$ glucose $(5 \mathrm{mM})$ metabolism into $\mathrm{CO}_{2}$ and lipids were compared in retroperitoneal adipocytes from age-matched ( $84 \mathrm{~d}$ ) male and female rats. In addition, the activity of fatty acid synthetase, one of the key lipogenic enzymes, was determined. Fat cell size was not significantly larger in females than in males (0.238 vs. $0.209 \mu$ g lipid per cell). At insulin concentrations $\leqslant 1.6 \mathrm{nM}$, adipocytes from females bound significantly more insulin than did adipocytes from males, due to an increased apparent affinity of the receptors for insulin. Accordingly, the sensitivity of glucose transport to insulin was greater in females than in males: insulin concentration eliciting half-maximal stimulation (ED $\left.\mathbf{5 0}_{\mathbf{5 0}}\right)$ $=0.19 \mathrm{nM}$ vs. $0.41 \mathrm{nM}$. At maximal insulin stimulation the rates of glucose transport (12 times the basal values) were similar in the two sexes. In contrast, the maximal effect of insulin on glucose conversion to $\mathrm{CO}_{2}$ plus lipids was much greater in the adipocytes from females than males (increment over basal: 472 vs. $249 \mathrm{nmol} / \mathbf{1 0}^{6}$ cells per 2 h). Fatty acid synthesis contributed $\sim 40 \%$ of the incremental difference between the two types of adipocytes, while glyceride-glycerol synthesis contributed $<10 \%$. The insulin dose-response curves for adipocytes from females were shifted to the left for all the metabolic pathways investigated. The mean $\mathrm{ED}_{\mathbf{5 0}}$ for total glucose metabolism in females was $50 \%$ of that in males $(0.07$ nM vs. 0.15 nM). Marked sex-associated differences in the action of insulin on glucose metabolism were also observed in subcutaneous inguinal adipocytes (increment over basal: 137 and $56 \mathrm{nmol} / 10^{6}$ cells per $2 \mathrm{~h}, \mathbf{E D}_{50}=0.13 \mathrm{nM}$ and $0.30 \mathrm{nM}$ in females and males, respectively). The intracellular capacity to metabolize glucose through the fatty acid synthesis pathway, as assessed by FAS activity, was higher in adipocytes from females than in those from males and was greater in retroperitoneal than in inguinal adipocytes. Furthermore, by plotting the individual data, a highly significant correlation $(r=0.92$,
\end{abstract}

Address reprint requests to Dr. Guerre-Millo, INSERM U. 177, Institut Biomédical des Cordeliers, 15-21 rue de l'Ecole de Médicine, 75270 Paris Cedex 06, France.

Received for publication 21 August 1984 and in revised form 5 March 1985

J. Clin. Invest.

(c) The American Society for Clinical Investigation, Inc.

0021-9738/85/07/0109/08 \$1.00

Volume 76, July 1985, 109-116
$P<0.001)$ was found between the absolute effect of insulin on glucose metabolism at maximal stimulation and the fatty acid synthetase activity of the cells.

These results indicate that the response of glucose metabolism to insulin in adipocytes from female as compared with male rats is characterized by two main features: (a) an increased sensitivity primarily due to an increase in insulin binding, and (b) an increased responsiveness closely associated with a postreceptor increase in the lipogenic capacity of the cell. These findings might be relevant to the differential disposition of male and female rats to develop fatness.

\section{Introduction}

The regulation of glucose metabolism by insulin in adipocytes from male rats has been the subject of numerous studies. In contrast, glucose metabolism in adipocytes from female rats has been poorly documented. Moreover, there is some discrepancy among the few papers dealing with this issue, as female adipocytes were reported to be either very responsive (1-3) or poorly responsive (4-6) to insulin and to display a maximal response either within the physiological concentration range of the hormone (1-3) or at much higher concentrations (7). We have recently shown that gonadal adipocytes from female rats (paraovarian) are as exquisitely responsive to insulin as gonadal adipocytes from age-matched male rats (epididymal) (8). In addition, paraovarian fat cells exhibit a significantly greater sensitivity to insulin than epididymal fat cells at the levels of both glucose transport and glucose metabolism. These findings, obtained from fat depots that were not exactly alike in males and females, do not allow us to ascertain the presence of sex differences in insulin's action on adipocytes. Nevertheless, they suggest that insulin's ability to stimulate glucose metabolism might be enhanced in adipocytes from female as compared with male rats. The presence of sex-associated differences in the effects of insulin on adipocytes might have physiological relevance to the differing tendencies in males and females to gain body fat. This has been shown extensively in humans where young adult females have $\sim 15-30 \%$ body fat and males have only $10-20 \%$, with the divergence between sexes developing mostly after puberty (9). Sex differences in body fat, although much less striking, have been reported also in rat where, after weaning, females have been shown to deposit more fat than males for the same increase in body weight (10).

Those observations prompted us to investigate the response of glucose metabolism to insulin in adipocytes from female rats and in adipocytes from male rats, compared site-to-site. We were careful to examine several adipose tissue locations, since it has been clearly established that there are large regional differences in glucose metabolism and its response to insulin in male rats (11). As age has also been shown to play a major 
role in the magnitude of the response to insulin in epididymal adipocytes (12-14), this comparison was carried out in male and female rats carefully matched for age. The data to be presented support the view that adipocytes from females are both more responsive and more sensitive to insulin than adipocytes from male rats, regardless of the anatomical location of the adipose tissue. Furthermore, they indicate that sexrelated alterations in insulin's ability to stimulate glucose metabolism in adipocytes are a consequence of changes localized to the levels of both insulin binding and postreceptor lipogenic capacity.

\section{Methods}

Animals. Age-matched male and female Wistar rats were obtained from Centre d'Elevage Robert Janvier (Le Genest, France) at the age of $45 \pm 2 \mathrm{~d}$. They were housed at $22-23^{\circ} \mathrm{C}$ on a fixed 12-h light $(7: 00$ a.m. to 7:00 p.m.)/12-h dark cycle and fed stock diet (Usine d'Alimentation Rationnelle, Epinay, France) containing, by weight, 23\% casein, $37 \%$ dextrose, $26 \%$ starch, $2 \%$ vitamin mixture, $6 \%$ fat, and $6 \%$ cellulose. Rats were used at $84 \pm 2 \mathrm{~d}$.

Preparation of isolated adipocytes. In each experiment, 2-3 female rats and 1-2 male rats closely matched in age were used. They were killed between 9 a.m. and 10 a.m. by cervical dislocation. The two retroperitoneal fat pads, and in some experiments, the two subcutaneous fat pads in the inguinal region, were removed and weighed. The tissues from animals of the same group were pooled before being minced with scissors. Isolated adipocytes then were prepared by digesting the tissue in Krebs-Ringer-bicarbonate buffer, pH 7.4, containing 3\% bovine serum albumin (Sigma Chemical Co., St. Louis, MO), $5 \mathrm{mM}$ glucose, half the recommended $\mathrm{Ca}^{2+}$ concentration, and $1 \mathrm{mg} / \mathrm{ml}$ of collagenase (Boehringer Mannheim Diagnostics, Inc., Houston, TX), as described by Rodbell (15). After $1 \mathrm{~h}$ at $37^{\circ} \mathrm{C}$, the cells were filtered through a $190-\mu \mathrm{m}$ nylon screen, washed 3 times in the appropriate collagenase-free buffer by allowing the cells to float, and then resuspended in the same buffer. Mean fat cell diameter was measured using a photomicrographic method as previously described (16).

Glucose metabolism studies. The major pathways of glucose metabolism in adipocytes (i.e., incorporation into $\mathrm{CO}_{2}$, glyceride-fatty acids, and glyceride-glycerol) were studied as previously described (17). In brief, duplicate or triplicate aliquots $(0.5 \mathrm{ml})$ of adipocytes (between $3 \times 10^{5}$ to $6 \times 10^{5}$ cells) suspended in Krebs-Ringer-bicarbonate buffer, pH 7.4, containing 3\% serum albumin and $5 \mathrm{mM}$ glucose were incubated at $37^{\circ} \mathrm{C}$ in plastic vials containing $2 \mathrm{ml}$ of the same buffer, [U $-{ }^{14} \mathrm{C}$ ]glucose $(300 \mathrm{mCi} / \mathrm{mmol}$, Centre d'Etudes Nucléaires Saclay, 91191 Gifsur Yvette, France) and insulin concentrations ranging from 0 to $2.5 \mathrm{nM}$. After $2 \mathrm{~h}$, the incubation was ended by adding $0.5 \mathrm{ml} 6$ $\mathrm{N} \mathrm{H}_{2} \mathrm{SO}_{4}$ to the flasks, and ${ }^{14} \mathrm{CO}_{2}$ was collected in $0.3 \mathrm{ml}$ of hyamine added to a center well. The contents of the incubation flasks then were extracted with a heptane-isopropanol mixture (18) and an aliquot was used to measure ${ }^{14} \mathrm{C}$ incorporation into total lipids. The remainder of the lipids was saponified and used to measure ${ }^{14} \mathrm{C}$ incorporation into fatty acids (organic phase) and glycerol (aqueous phase). Total glucose utilization was estimated by summing the incorporation of ${ }^{i 4} \mathrm{C}$-glucose into $\mathrm{CO}_{2}$ and lipids. Note that this may be an underestimate of total glucose utilization, since lactate has been shown by us and others (11, $13,19,20)$ to represent a non-negligible glucose metabolite in adipose tissue from male rats. We have found that this also applies to adipocytes from female rats (Burnol, A. F., M. Guerre-Millo, M. Lavau, and J. Girard, unpublished observations).

Insulin binding studies. 0.6- $\mathrm{ml}$ samples of the fat cell suspensions in Krebs-Ringer-phosphate buffer, $\mathrm{pH} 7.4$, containing $2 \%$ serum albumin and $5 \mathrm{mM}$ glucose, were incubated for $1 \mathrm{~h}$ at $37^{\circ} \mathrm{C}$ or $16^{\circ} \mathrm{C}$ with [A $14^{125}$ I] monoiodoinsulin $(300 \mathrm{mCi} / \mathrm{mg}$, CEA Saclay, France), with or without the addition of unlabeled insulin at final concentrations ranging from 0.03 to $19 \mathrm{nM}$, in a final volume of $0.8 \mathrm{ml}$. The incubations were ended by the oil centrifugation procedure described by Gammeltoft \& Gliemann (21). Data are reported as specific binding, which was obtained by substracting from total binding the amount of radioactivity that remained bound to the cells in the presence of a large excess of unlabeled insulin $(15 \mu \mathrm{M})$. Nonspecific binding averaged between 5 and $10 \%$ of the total binding. The radioactivity was measured in a Gamma Spectrometer (Gamma 4000, Beckman Instruments, Inc., Fullerton, CA).

Glucose transport studies. Glucose transport was assessed by measuring the cell-associated radioactivity after rapid incubation of adipocytes in the presence of $50 \mu \mathrm{M}\left[6-{ }^{14} \mathrm{C}\right]$ glucose, using a method similar to that recently described by Gliemann et al. (22). Duplicate or triplicate aliquots $(0.475 \mathrm{ml})$ of the fat cell suspensions in KrebsRinger-phosphate buffer, $\mathrm{pH} 7.4$, containing $2 \%$ serum albumin and 2 $\mathrm{mM}$ pyruvate, were preincubated $45 \mathrm{~min}$ at $37^{\circ} \mathrm{C}$, in the absence or presence of insulin at concentration ranging from 0.03 to $2.5 \mathrm{nM}$. The assays were performed at $37^{\circ} \mathrm{C}$ with magnetic stirring and were initiated by adding $50 \mu \mathrm{M}\left[6-{ }^{14} \mathrm{C}\right]$ glucose $(45 \mathrm{mCi} / \mathrm{mmol}$; CEA, Saclay, France). $15 \mathrm{~s}$ later, the assay was ended by subjecting $300-\mu \mathrm{l}$ aliquots of the incubation mixture to the oil centrifugation procedure described by Gammeltoft and Gliemann (21). The radioactivity in the cell layer was corrected for $\left[{ }^{14} \mathrm{C}\right]$ glucose trapped in the extracellular water by using $\left[{ }^{3} \mathrm{H}\right]$ inulin $(3 \mathrm{Ci} / \mathrm{mmol}$; Amersham Corp., Arlington Heights, IL). $\left[6^{14} \mathrm{C}\right] g l u c o s e$ was chosen over $\left[\mathrm{U}-{ }^{14} \mathrm{C}\right]$ glucose or $\left[1-{ }^{14} \mathrm{C}\right]$ glucose to avoid losing labeled $\mathrm{CO}_{2}$ through the pentose phosphate cycle. Pyruvate was added to the medium to dilute the labeled metabolites into a large pool and minimize their loss. In preliminary experiments (Lavau, M., and $\mathrm{M}$. Guerre-Millo, unpublished observations) we have shown that there was no measurable ${ }^{14} \mathrm{CO}_{2}$ production over a 30 -s incubation period and that, within the ranges of time ( $15 \mathrm{~s})$ and glucose concentration $(50 \mu \mathrm{M})$ used here, the cell-associated radioactivity was linear with both time and glucose concentration. Compared with 2-deoxyglucose and 3-O-methyl glucose (the two glucose analogs generally used in glucose transport studies), $\left[6-{ }^{14} \mathrm{C}\right]$ glucose gives similar, or perhaps even higher, responses to insulin (unpublished observations).

Determination of fatty acid synthetase activity. Fat cells suspended in ice-cold $0.25 \mathrm{M}$ sucrose containing $3 \mathrm{mM}$ dithiothreitol and $1 \mathrm{mM}$ EDTA at pH 6.8, were sonicated $15 \mathrm{~s}$ and then centrifuged at 100,000 $g$ at $0^{\circ} \mathrm{C}$ for $60 \mathrm{~min}$. Fatty acid synthetase activity was measured spectrophotometrically in the supernatants by following the oxidation of NADPH in the presence of acetyl-coenzyme A (CoA) and malonylCoA according to the method of Martin et al. (23). The assays were run at $37^{\circ} \mathrm{C}$ in duplicate, using a Perkin-Elmer model 555 Spectrophotometer (Uberlingen, Germany). Conditions were selected to ensure linear rates with respect to time (up to 8-10 $\mathrm{min}$ ) and sample concentration.

Liquid scintillation counting. ${ }^{14} \mathrm{C}$ and ${ }^{3} \mathrm{H}$ isotopes were counted in a liquid scintillation spectrometer with stored quench calibration curves and automatic disintegrations per minute $(\mathrm{dpm})$ calculation (LS 6800; Beckman Instruments, Inc.). Liquid scintillators were ReadySolv MP (multipurpose) or Ready-Solv NA (nonaqueous) (Beckman Instruments, Inc.).

Statistical analysis. Results are expressed as the mean \pm SEM. All $P$ values were obtained using the unpaired $t$ test, unless otherwise stated.

\section{Results}

Rat body weight was measured from $45 \mathrm{~d}$ of age until the experiment time. The growth patterns were very different between the two sexes (not shown). Male rats steadily gained weight, whereas the growth rate of female rats slowed after 65 d of age. These observations point out the lack of precision of weight in characterizing adult female rats. As shown in Table $\mathrm{I}$, the male rats used were $80 \mathrm{~g}$ heavier than the female rats at 3 mo of age.

1. Abbreviations used in this paper: $\mathrm{CoA}$, coenzyme $\mathrm{A} ; \mathrm{ED}_{50}$, insulin concentration eliciting half-maximal stimulation. 
Table I. Retroperitoneal and Inguinal Adipose Tissue Weights and Fat Cell Sizes in Male and Female Rats*

\begin{tabular}{clll}
\hline & & Adipose tissue site & \\
\cline { 3 - 4 } & & Retroperitoneal & Inguinal \\
\hline $\begin{array}{c}\text { Total adipose } \\
\text { tissue weight } \\
(g)\end{array}$ & Male & $1.19 \pm 0.07(27) \ddagger$ & $2.28 \pm 0.17(10) \ddagger$ \\
$\begin{array}{c}\text { Fat cell size } \\
(\text { ng lipid/cell })\end{array}$ & Female & $0.85 \pm 0.04(43)$ & $1.69 \pm 0.07(15)$ \\
Adipose tissue & Male & $209 \pm 18(17)$ & $94 \pm 9(5)$ \\
weight (\%) & Female & $238 \pm 25(17)$ & $96 \pm 6(5)$ \\
Body weight & & $0.45 \pm 0.03(27)$ & $0.84 \pm 0.05(10)$ \\
\hline
\end{tabular}

* Age-matched $(84 \pm 2$ d) male and female rats weighing $267 \pm 3 \mathrm{~g}$ $(n=27)$ and $191 \pm 2 \mathrm{~g}(n=43)$, respectively. Values are the means \pm SEM for the number of determinations given in parentheses. $\ddagger P<0.01$ vs. female rats.

Adipose tissue weights and fat cell size are shown in Table I. Along with their larger body weight, male rats had larger adipose tissue depots than females, so that the ratios of tissue weight to body weight were nearly identical in the two groups. In contrast to fat pad weights, fat cell sizes were not statistically different in females and males at this age. This implies that there were fewer fat cells in females than in males in both the inguinal and retroperitoneal sites. Table I further shows that 3-mo-old female rats presented regional differences in fat cell size that were strikingly similar to those observed in agematched male rats, with retroperitoneal fat cells $\sim 2.8$-fold larger than subcutaneous inguinal fat cells $(P<0.01)$.

The insulin dose response curves for $\mathrm{D}\left[\mathrm{U}-{ }^{14} \mathrm{C}\right] \mathrm{glucose}$ metabolism in retroperitoneal adipocytes from female and male rats are illustrated in Fig. 1 . In the basal state ( 0 insulin),

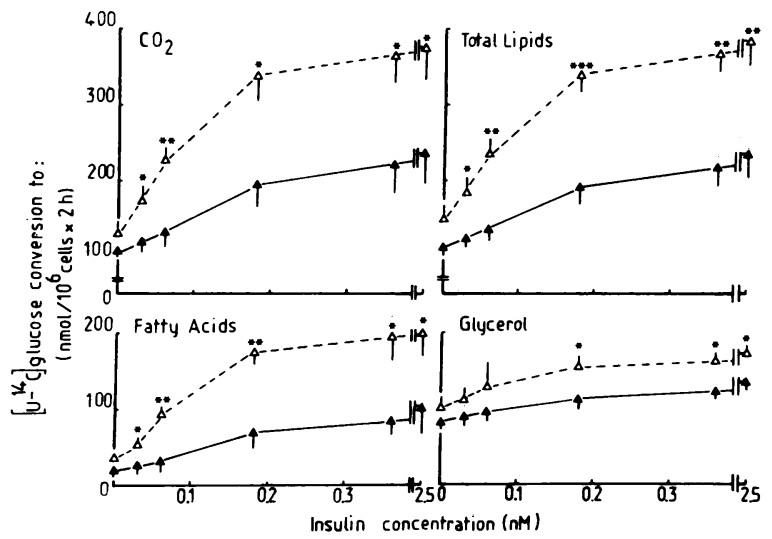

Figure 1. Insulin dose-response curves of glucose metabolism in retroperitoneal adipocytes from age-matched male $(\Delta)$ and female $(\Delta)$ rats. Results are the mean \pm SEM of mean values obtained from duplicate or triplicate samples in five individual experiments. In each experiment, the retroperitoneal adipose tissues from two male and three female rats were pooled. Fat cells were incubated in $2.5 \mathrm{ml}$ Krebs-Ringer-bicarbonate buffer containing $3 \%$ albumin, $\mathrm{pH}=7.4$, at $37^{\circ} \mathrm{C}$ for $2 \mathrm{~h}$. D- $\left[\mathrm{U}-{ }^{14} \mathrm{C}\right]$ glucose was present at a final concentration of $5 \mathrm{mM}$. ${ }^{*} P<0.05 ;^{* *} P<0.01{ }^{* * *} P<0.001$ vs. male rats. sex did not significantly influence either the rate or pattern of glucose metabolism. The glucose conversion to $\mathrm{CO}_{2}$ was equivalent to its conversion to lipids and the incorporation of ${ }^{14} \mathrm{C}$ into the glyceride-glycerol moiety was threefold greater than that into the fatty acid moiety in both groups of rats. In contrast, the effect of insulin on glucose metabolism differed sharply in the adipocytes of male and female rats. The adipocytes of female rats exhibited a much greater response to insulin than those of male rats at both submaximal and maximal insulin concentrations. In terms of percent increase over basal, the effect of insulin on glucose oxidation or total lipid labeling averaged $30 \%$ in females vs. $10 \%$ in males at the lowest insulin concentration tested $(0.03 \mathrm{nM})$ and $190 \%$ vs. $110 \%$ at maximal stimulation. In adipocytes from female as well as male rats, the insulin effect varied greatly according to the metabolic pathway studied, the effect on the incorporation of ${ }^{14} \mathrm{C}$ into fatty acids being several-fold greater than the effect on the incorporation of ${ }^{14} \mathrm{C}$ into glyceride glycerol in both sexes.

Substantial differences in absolute effects (increment above basal values) existed between the two sexes at all the insulin concentrations tested (Fig. 2). In the low concentration range of insulin $(<0.18 \mathrm{nM})$, the adipocytes from female rats responded by an increment in total glucose metabolism nearly fourfold higher than that of male adipocytes; the increment in females was still twice that in males at maximal insulin stimulation. Fatty acid synthesis contributed $\sim 40 \%$ of the incremental differences between the two types of adipocytes, while glycerol synthesis contributed $<10 \%$.

Scrutiny of the dose response curves illustrated in Fig. 1 strongly suggested that the curves obtained with adipocytes from female rats were left-shifted compared with those obtained with adipocytes from male rats. This was better shown by plotting the data as percentages of the maximal effect observed at $2.5 \mathrm{nM}$ insulin as shown in Fig. 3 for total glucose metabolism. The curves for adipocytes from female rats were shifted to the left for all the metabolic pathways investigated, indicating a higher sensitivity to insulin as compared with adipocytes from male rats (data not shown). The degree of left-shift was assessed by the difference in the dose of insulin

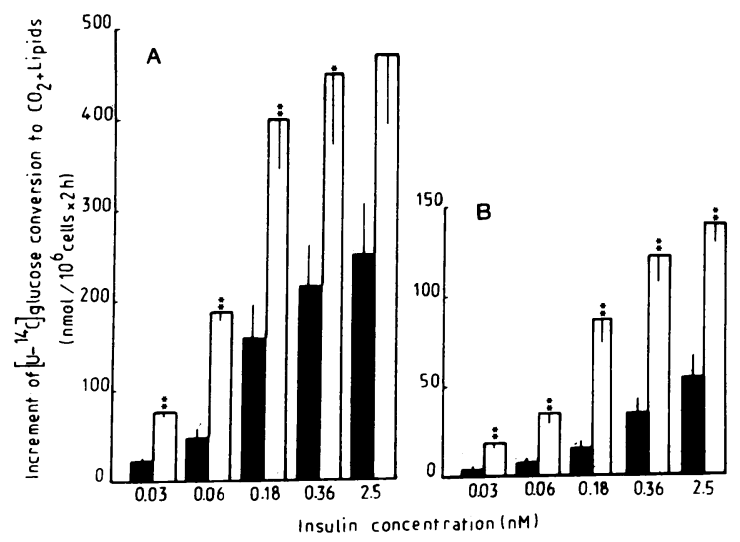

Figure 2. Absolute insulin effect (increment over basal) on glucose conversion to $\mathrm{CO}_{2}+$ lipids in retroperitoneal $(A)$ and inguinal $(B)$ adipocytes from age-matched male ( $\triangle)$ and female ( $\square$ ) rats. Data are from the experiments described in Fig. 1 and Fig. $4 .{ }^{*} P<0.05 ;{ }^{* *} P$ $<0.01$ vs. male rats. 


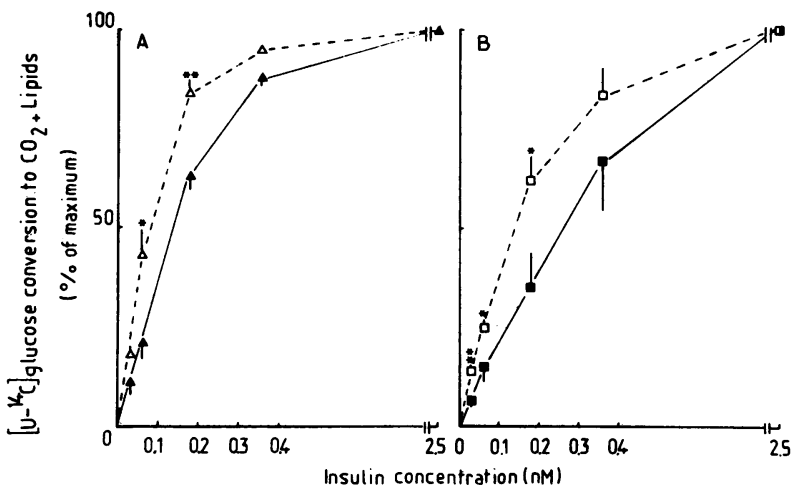

Figure 3. Insulin effect expressed as percent of the maximum response on glucose conversion to $\mathrm{CO}_{2}+$ lipids in retroperitoneal $(A)$ and inguinal $(B)$ adipocytes from age-matched male (solid symbols) and female (open symbols) rats. Data are from the experiments described in Fig. 1 and Fig. $4 .{ }^{*} P<0.05 ;{ }^{* *} P<0.01$ vs. male rats.

eliciting half maximal stimulation $\left(E D_{50}\right)$ between the two groups. The mean $\mathrm{ED}_{50}$ of insulin for total glucose metabolism, calculated from the individual dose response curves, was $50 \%$ lower in females than in males $(0.07 \pm 0.013 \mathrm{nM}$ vs. $0.15 \pm 0.012$ $\mathrm{nM} ; P<0.01$ ). In addition, the maximal stimulation of all the pathways of glucose metabolism in retroperitoneal adipocytes from female rats was achieved at $0.18 \mathrm{nM}$ insulin, a value well within the physiological concentration range of the hormone.

To determine whether the greater sensitivity and responsiveness of glucose metabolism to insulin observed in retroperitoneal adipocytes from female rats is a general feature of the entire adipose tissue mass, we investigated whether sex differences could be detected at another adipose tissue site. Subcutaneous inguinal adipocytes were chosen since Fried et al. (11) had shown large differences in the responsiveness and sensitivity to insulin between retroperitoneal and subcutaneous dorsal adipocytes in male rats. These results are illustrated in Fig. 2 and Fig. 4. Under basal conditions, adipocytes from

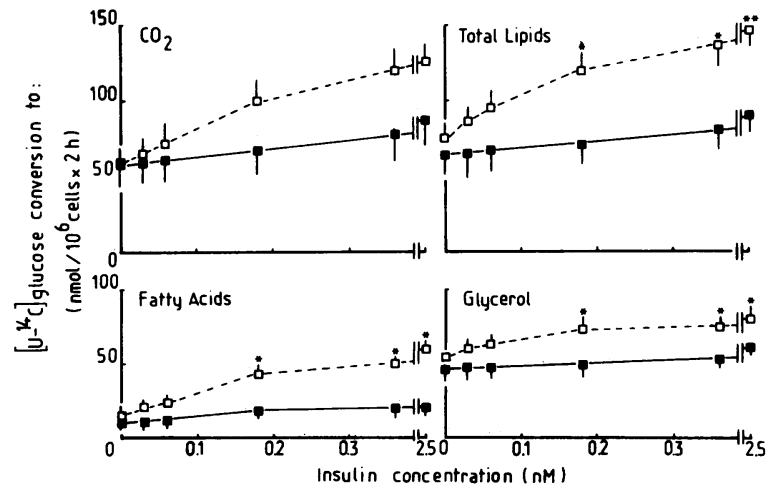

Figure 4. Insulin dose-response curves of glucose metabolism in inguinal adipocytes from age-matched male (- -$)$ and female $(--\square--)$ rats. Results are the mean \pm SEM of mean values obtained from duplicate or triplicate samples in five individual experiments. In each experiment, the inguinal adipose tissues from two male and three female rats were pooled. The inguinal adipose tissues were removed from the rats used in the experiments described in Fig. 1. Fat cells were incubated as described in the legend of Fig. 1. female rats showed the same rates and the same pattern of $\left[\mathrm{U}-{ }^{14} \mathrm{C}\right]$ glucose metabolism as adipocytes from male rats. Upon addition of insulin, adipocytes from male and female rats again differed sharply. In terms of both the increases over basal and absolute increments, the effects of subphysiological insulin concentrations $(<0.18 \mathrm{nM})$ on the inguinal adipocytes from male rats were barely detectable. In contrast, insulin had a clear effect on adipocytes from females, increasing glucose conversion to $\mathrm{CO}_{2}$ plus lipids by $25 \%$ at $0.06 \mathrm{nM}$ with an absolute effect fivefold higher than in the adipocytes from male rats. At maximal stimulation, the increase over basal in total glucose metabolism amounted to $105 \%$ in females vs. $46 \%$ in males, with an absolute effect nearly threefold higher in females than in males. The insulin dose response curve for total glucose metabolism, expressed as a percent of the maximal effect, was again significantly left-shifted in females as compared with males, as illustrated in Fig. $3 B$ with a mean $\mathrm{ED}_{50}$ of $0.13 \pm 0.017 \mathrm{nM}$ in females vs. $0.30 \pm 0.071 \mathrm{nM}$ in males $(P$ $<0.05$ ). Thus, sex differences in the effect of insulin on adipocyte glucose metabolism are not only present at the level of the inguinal fat depot, but are even more marked than those observed at the level of the retroperitoneal fat depot.

To document the mechanisms behind the increased sensitivity and responsiveness to insulin exhibited by adipocytes of female as compared with male rats, we examined whether there were sex-associated changes at the insulin receptor level. This question was investigated in retroperitoneal adipocytes. As shown in Fig. 5, specific insulin binding was twofold higher in adipocytes from female rats than from male rats at tracer insulin concentration $(0.034 \mathrm{nM})$. The relative difference between the two groups narrowed with increasing insulin concentration. Above $1.6 \mathrm{nM}$, adipocytes from females did not bind significantly more insulin than adipocytes from male rats.

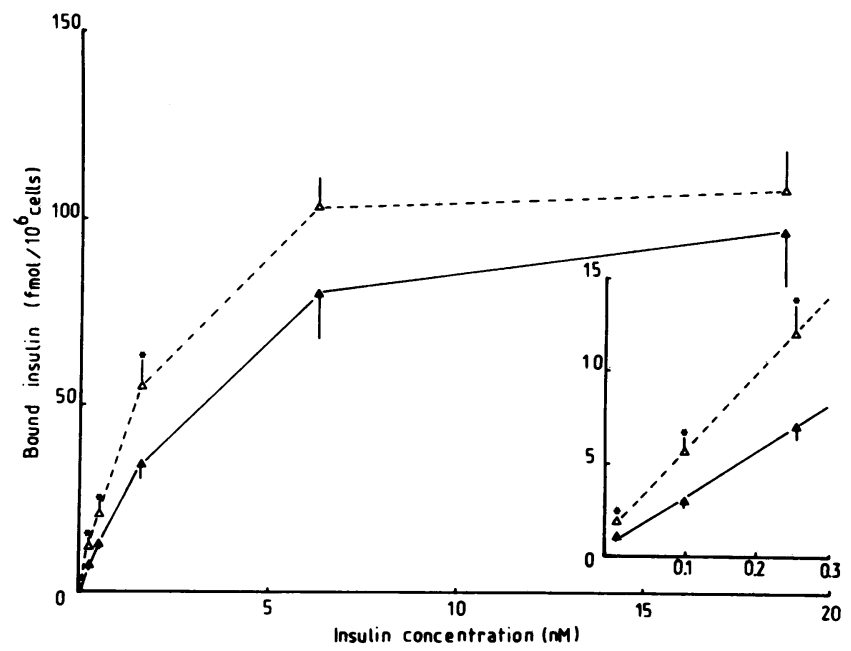

Figure 5. Insulin binding to retroperitoneal adipocytes from agematched male $(-\Delta-)$ and female $(--\Delta--)$ rats. Results are the mean \pm SEM of mean values obtained from duplicate samples in four individual experiments. In each experiment the retroperitoneal adipose tissues from one male and two female rats were pooled. Cells were incubated in $0.8 \mathrm{ml}$ Krebs-Ringer-phosphate buffer containing $2 \%$ albumin, $5 \mathrm{mM}$ glucose, $\mathrm{pH} 7.4$, at $37^{\circ} \mathrm{C}$ with [A14 ${ }^{125} \mathrm{I}$ ] insulin and increasing amounts of unlabeled insulin, for $45 \mathrm{~min}$. Data were corrected for nonspecific binding. Note the expanded scales in the inserted figure. ${ }^{*} P<0.05$ vs. male rats. 
These data were obtained at $37^{\circ} \mathrm{C}$, the temperature at which part of the cell-associated radioactivity may represent internalized insulin. Therefore, an additional series of four experiments was performed at $16^{\circ} \mathrm{C}$, the temperature at which internalization of insulin is partially inhibited $(24,25)$. The data obtained at $16^{\circ} \mathrm{C}$ (not shown) confirmed our observations at $37^{\circ} \mathrm{C}$, indicating that the difference in the cell-associated insulin between the two sexes reflected primarily a difference in the insulin binding to the cell surface. The data from the binding studies at $37^{\circ} \mathrm{C}$ have been plotted according to Scatchard's analysis (26). It has been pointed out that the Scatchard analysis only approximates the number and affinity of insulin binding sites $(27,28)$. It was used here solely for comparative purposes. Over the range of insulin concentrations tested, only the second component of the curvilinear plot was substantiated and used for calculations. A significant increase in the apparent affinity of the insulin receptors was found in the adipocytes from females as compared with males (apparent dissociation constant: $2.6 \pm 0.23 \mathrm{nM}$ in females vs. $4.3 \pm 0.48 \mathrm{nM}$ in males, $P<0.05)$. No significant difference could be seen between the two sexes in the apparent number of insulin receptors $(83,000$ per cell in females vs. 76,000 per cell in males). Fig. 5 and Fig. 1 clearly show that the maximal insulin effect on glucose metabolism was elicited by a receptor occupancy of $<10 \%$ in adipocytes from both sexes.

These sex-associated changes in insulin binding agree with the finding that glucose metabolism is more sensitive to insulin in adipocytes from female rats than from male rats. However, they do not account for the differences seen in the responsiveness of glucose metabolism to supramaximal concentrations of insulin. Therefore, postreceptor differences between the two sexes must be postulated. We investigated the possibility that changes could be located at the level of glucose transport. The rate of glucose transport was assessed in retroperitoneal adipocytes by measuring the cell-associated radioactivity after incubation with $50 \mu \mathrm{M}\left[6{ }^{14} \mathrm{C}\right]$ glucose during $15 \mathrm{~s}$. The data in Fig. $6 A$ show that basal and maximal insulin-stimulated glucose transport rates were identical in adipocytes from the two sexes with insulin stimulating the rates about 12 -fold in both. Consistent with the increased insulin binding found in the adipocytes from female rats at low insulin concentrations, a greater insulin sensitivity of glucose transport was clearly demonstrated in females by expressing the dose-response curve data as percentages of the maximal insulin stimulation (Fig. $6 \mathrm{~B}$ ). The mean $\mathrm{ED}_{50}$ of insulin for glucose transport, calculated from the individual dose response curves, was $50 \%$ lower in female than in male rats $(0.19 \pm 0.008 \mathrm{nM}$ vs. $0.41 \pm 0.088 \mathrm{nM} ; P<0.05)$. The mean $\mathrm{ED}_{50}$ of insulin for glucose transport was higher than the $\mathrm{ED}_{50}$ of insulin for glucose metabolism in both sexes.

The finding of the same glucose transport rates in adipocytes from male and female rats at maximal insulin stimulation strongly suggested that the demonstrated differences in insulin responsiveness of glucose metabolism between sexes were attributable to changes located beyond the glucose transport step. Since fatty acid synthesis represented a large proportion of the incremental difference in glucose metabolism between the adipocytes from female and male rats, we postulated that an increase in the activity of fatty acid synthetase, which has been shown to be a rate-limiting enzyme for overall lipogenesis under certain metabolic conditions (29), might explain the enhancement of the effect of insulin in female adipocytes.

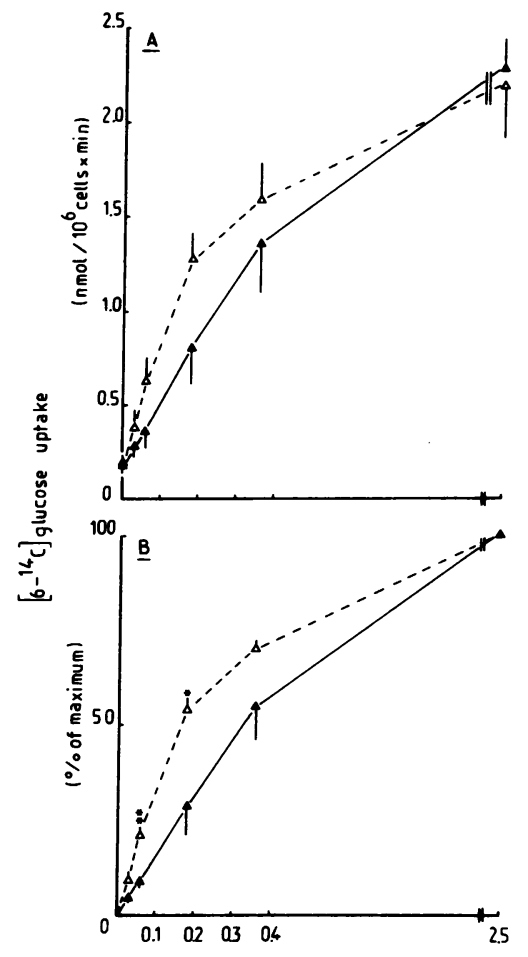

Figure 6. $(A)$ Insulin dose-response curves of glucose transport in retroperitoneal adipocytes from age-matched male $(-\Delta-)$ and female $(--\Delta--)$ rats. $(B)$ Data expressed as percent of the maximum response to insulin. Results are the means \pm SEM of mean values obtained from duplicate or triplicate samples in four individual experiments. In each experiment, the retroperitoneal adipose tissues from one male and two female rats were pooled. Cells were incubated in $0.53 \mathrm{ml}$ Krebs-Ringer-phosphate buffer containing 2\% albumin, $2 \mathrm{mM}$ pyruvate, pH 7.4 , at $37^{\circ} \mathrm{C}$ with $50 \mu \mathrm{M}$ D- $\left[6-{ }^{-14} \mathrm{C}\right]$ glucose for $15 \mathrm{~s}$. The radioactivity in the cell pellets was corrected for extracellular water space by using $\left[{ }^{3} \mathrm{H}\right]$ inulin. ${ }^{*} P<0.05 ;{ }^{* *} P<0.01$ vs. male rats.

Therefore, fatty acid synthetase activity was measured in homogenates of adipocytes from the same cell suspensions as those used in the metabolic studies. We found that the adipocytes from female rats showed a higher enzyme activity than those from males in both the retroperitoneal and inguinal adipose tissue sites (Table II). In addition, this enzyme activity was lower in subcutaneous than in retroperitoneal adipocytes

Table II. Fatty Acid Synthetase Activity in Retroperitoneal and Inguinal Adipocytes from Age-matched Male and Female Rats*

\begin{tabular}{lll}
\hline Site & Retroperitoneal & Inguinal \\
\hline Male rats & $19 \pm 4.4$ & $10 \pm 1.9 \S$ \\
Female rats & $42 \pm 9.2 \ddagger$ & $18 \pm 2.3 \ddagger \S$ \\
\hline
\end{tabular}

The enzyme activity was measured in the cells used for the experiments described in Fig. 1 and Fig. 4. Data are the means \pm SEM of mean values obtained from duplicate samples in five experiments for each adipose tissue.

* Results given in nanomols NADPH $/ 10^{6}$ cells $\times$ min $\ddagger P<0.05$ (compared with the values of male rats). $\S P<0.05$ by paired $t$ test (compared with the retroperitoneal values). 
in both sexes. When the relationship between the effect of insulin on total glucose metabolism and the activity of fatty acid synthetase was further examined by plotting the individual values of enzyme activity against the absolute effect of the hormone (increment over basal) at maximal stimulation (Fig. $7)$, a strong correlation was seen $(r=0.92, P<0.001)$.

\section{Discussion}

In agreement with previous findings in male rats (11), this study shows that anatomic site is a major factor in the response of glucose metabolism to insulin in fat cells. The subcutaneous inguinal adipocytes, like the subcutaneous dorsal adipocytes (11), were shown to be much less responsive and less sensitive to insulin than the retroperitoneal adipocytes. We provide evidence that the adipocytes from female rats exhibit large and similar metabolic differences between these two regions.

This study, addressed to comparing the response of adipocytes from female and male rats to insulin, confirms our previous observations of gonadal adipose tissue (paraovarian versus epididymal), that adipocytes from female rats are more sensitive to insulin than adipocytes from male rats with respect to glucose metabolism (8). The present data, based on comparisons of fat cells of similar size from the same fat depots in male and female rats closely matched for age, establish unequivocally the presence of sex differences in the response of adipocytes to insulin. The major findings are that glucose metabolism is more sensitive and more responsive to insulin in adipocytes from female than from male rats in both the retroperitoneal and the inguinal fat depots.

To gain insight into the mechanism of the observed sexrelated differences in the action of insulin on adipocyte glucose

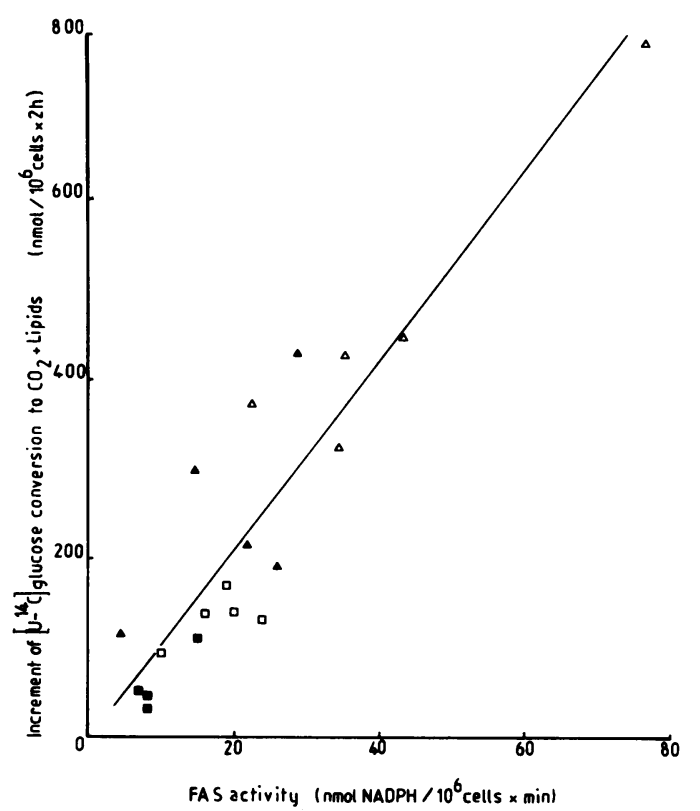

Figure 7. Relationship between fatty acid synthetase (FAS) activity and absolute insulin effect (increment over basal) on glucose conversion to $\mathrm{CO}_{2}+$ lipids in retroperitoneal $(\Delta, \Delta)$ and inguinal $(n, \square)$ adipocytes from age-matched male (black symbols) and female (open symbols) rats. FAS activity was measured in the cells used for the experiments described in Fig. 1 and Fig. 4. $r=0.92 ; P<0.001$. metabolism, we further documented the effect of sex at the levels of insulin binding and glucose transport. The study, carried out in retroperitoneal fat cells, showed that insulin binding is increased in the adipocytes from female as compared with male rats but only at submaximal insulin concentrations, as the result of a greater apparent affinity of the receptors for insulin. The functional consequences of this change in insulin binding were examined at the level of glucose transport, a response proximal to hormone binding. As expected, adipocytes from female rats exhibited a greater sensitivity to insulin than did adipocytes from male rats, as manifested by a left-shift in the dose-response curve and an increased response at submaximal insulin concentration in the presence of a similar response at maximal insulin concentrations. The finding of the same insulin-induced increase in glucose transport rates in females and males implies, according to the concept developed by Cushman and Wardzala (30) and Suzuki and Kono (31), that the number of glucose transport systems translocated from the intracellular pool to the plasma membrane is identical in the two groups. This further suggests that sex might not affect the size of the intracellular pool of glucose transporters since it has been shown recently that the magnitude of the translocation in response to insulin is modulated by the size of this pool $(32,33)$.

These results indicate that the enhancement of the rates of glucose metabolism at high concentrations of insulin and glucose reflects a change located beyond the glucose transport step. This was also inferred from the well documented observation (34) that at physiological glucose concentration ( $5 \mathrm{mM})$, as used here, transport cannot be considered rate-limiting for metabolism in cells maximally stimulated by insulin. A very close association between the responsiveness of glucose metabolism to insulin and de novo fatty acid synthesis activity has been observed previously in adipocytes under various conditions such as feeding a high-fat diet $(13,17,35)$, aging $(13,36)$, and variations in the anatomic adipose tissue sites (11). The use of specific inhibitors of fatty acid synthetase, which decreased the ability of fat cells to increase overall glucose utilization in the presence of insulin, has underlined the importance of this enzyme in the modulation of insulin action (37). The present finding that fatty acid synthetase activity is significantly higher in adipocytes from females than in adipocytes from males in both the inguinal and the retroperitoneal depots supports this hypothesis. Moreover, a highly significant correlation is seen between the effect of insulin on glucose utilization and the activity of fatty acid synthetase, pointing to fatty acid synthetase as one of the postreceptor factors involved in regulating insulin action in adipocytes. Since changes in fatty acid synthetase activity are usually coordinated with changes in the activity of acetyl-CoA carboxylase $(11,38)$, it is likely that a relationship would have been found as well between acetyl-CoA carboxylase activity and the insulin effect on glucose metabolism.

The factors responsible for those findings are a matter of speculation at present. It seems reasonable to postulate that sex hormones, which have been shown to influence adiposity (39), are involved. Recent studies by Flint et al. (40) strongly suggest that progesterone may be implicated in the increased insulin binding capacity of rat adipocytes during pregnancy. Our current studies on insulin action in adipocytes of sexually immature male and female rats should help clarify this point. The evolution with age of these sex-related differences also deserves further investigation. 
Our data in the rat might be highly relevant to humans as suggested by two recent papers concerned with sex-associated differences in the effects of insulin on human adipocytes (41, 42). In these studies in humans, only adipocytes from the subcutaneous depots could be examined. Pedersen et al. (41), reporting on gluteal adipocytes from male and female subjects $\sim 25$ yr old, with normal body weight, showed that adipocytes from females were larger and bound more insulin per cell at tracer insulin concentrations, than adipocytes from males. Basal and insulin-stimulated 3-O-methyl-glucose transport and glucose metabolism per cell were also higher in females than in males. When these results were normalized to cell surface area, the rates of glucose transport were similar in the two sexes, whereas glucose conversion to both $\mathrm{CO}_{2}$ and lipids remained significantly higher in the adipocytes from females. The data obtained by Pedersen et al. (41) clearly showed that the absolute effect of insulin (increment over basal) was much higher in females than in males for glucose conversion to both $\mathrm{CO}_{2}$ (threefold higher) and lipids (twofold higher) over the entire range of insulin concentrations. These results fully agree with our observations in rats. However, in contrast to our finding in rats, the sensitivity to insulin was not increased in adipocytes from female human subjects despite the observed higher insulin binding.

Foley et al. (42), reporting on glucose transport in abdominal adipocytes from male and female subjects $\sim 27$ yr old with various degrees of obesity, also showed that the adipocytes from females were larger than those from males. In addition, and in perfect agreement with the observations of Pedersen et al. (41), basal and maximal insulin-stimulated glucose transport per cell were higher in the adipocytes from females than males, but were similar in the two sexes when expressed per surface area. Interestingly, Foley et al. (42) observed a greater sensitivity of glucose transport to insulin in adipocytes from women than from men.

The findings of an increase in the sensitivity and the responsiveness of glucose metabolism to insulin in adipocytes from female rats could have important implications for the intact organism, since these sex-related differences occur at low, physiologically relevant concentrations of insulin. Thus, a double mechanism would enable the adipose tissue in the two sexes to be differentially responsive to circulating insulin concentrations. However, the functional role of these observations has yet to be evaluated. If the elevated rates of lipogenesis in adipocytes from females were also to occur in vivo, they could ultimately lead to larger fat cell size. This remains to be documented in older rats since we did not observe any difference in fat cell size between the two sexes in the 3-mo-old rats used here. In relevance to our data, it has been observed that female rats are more susceptible than male rats to the fattening effect of western type diets, such as highfat and supermarket diets $(10,43,44)$. Further studies are needed to determine whether the sex-associated differences in the lipogenic effect of insulin on adipocytes described here are involved in the differential disposition of the two sexes to gain body fat.

\section{Acknowledgments}

We wish to thank Samuel W. Cushman for his careful reading of the manuscript, Colette Guichard for her excellent technical assistance, and Valérie Resve for typing the manuscript.

\section{References}

1. Craig, B. W., G. T. Hammons, S. M. Garthwaite, L. Jarett, and J. O. Holloszy. 1981. Adaptation of fat cells to exercise: response of glucose uptake and oxidation to insulin. J. Appl. Physiol. 51:15001506.

2. Wardzala, L. J., M. Crettaz, E. D. Horton, B. Jeanrenaud, and E. S. Horton. 1982. Physical training of lean and genetically obese Zucker rats: effect on fat cell metabolism. Am. J. Physiol. 1243:E418E426.

3. Olefsky, J. M., M. Saekow, and R. L. Kroc. 1982. Potentiation of insulin binding and insulin action by purified porcine relaxin. Ann. N. Y. Acad. Sci. 380:200-215.

4. Sutter-Dub, M. T., B. Dazey, M. T. Vergnaud, and A. M. Madec. 1981. Progesterone and insulin-resistance in the pregnant rat. I. In vivo and in vitro studies. Diabete. Metab. 7:97-104.

5. Sutter-Dub, M. T., A. Sfaxi, and P. Strozza. 1983. Glucose metabolism in the female rat adipocyte: lipid synthesis from glucose during pregnancy and progesterone treatment. J. Endocrinol. 97:207212.

6. Flint, D. J., P. A. Sinnet-Smith, R. A. Clegg, and R. G. Vernon. 1979. Role of insulin receptors in the changing metabolism of adipose tissue during pregnancy and lactation in the rat. Biochem. J. 182:421427.

7. Czech, M. P., C. C. Malbon, K. Kerman, W. Gitomer, and P. F. Pilch. 1980. Effect of thyroid status on insulin action in rat adipocytes and skeletal muscle. J. Clin. Invest. 66:574-582.

8. Guerre-Millo, M., A. Leturque, M. Lavau, and J. Girard. 1985. Effect of insulin on glucose transport and metabolism in isolated fat cells of gonadal adipose tissue from mature age-matched male and female rats. Biochem. J. 225:343-348.

9. Forbes, G. B. 1979. Body composition and the natural history of fatness. Obesity in America. G. A. Bray, editor. National Institutes of Health Publication No. 79-359. 95-102.

10. Schemmel, R., O. Michelsen, and Z. Tolgay. 1969. Dietary obesity in rats: influence of diet, weight, age and sex on body composition. Am. J. Physiol. 216:373-379.

11. Fried, S. K., M. Lavau, and F. X. Pi-Sunyer. 1982. Variations in glucose metabolism by fat cells from three adipose depots of the rat. Metabolism. 31:876-883.

12. DiGirolamo, M., and D. Rudman. 1968. Variations in glucose metabolism and sensitivity to insulin of the rats adipose tissue, in relation to age and body weight. Endocrinology. 82:1133-1141.

13. Lavau, M., M. Nadeau, and C. Susini. 1972. Metabolisme in vitro du tissu adipeux épididymäire du rat en état d'obésité nutritionnelle. Biochimie (Paris). 54:1057-1067.

14. DiGirolamo, M., M. D. Howe, J. Esposito, L. Thurman, and J. L. Owens. 1974. Metabolic patterns and insulin responsiveness of enlarging fat cells. J. Lipid Res. 15:332-338.

15. Rodbell, M. 1964. Metabolism of isolated fat cells. I. Effects of hormones on glucose metabolism and lipolysis. J. Biol. Chem. 239: 375-380.

16. Lavau, M., C. Susini, J. Knittle, S. Blanchet-Hirst, and M. R. C. Greenwood. 1977. A reliable photomicrographic method for determining fat cell size. Application to dietary obesity. Proc. Soc. Exp. Biol. Med. 156:251-256.

17. Lavau, M., S. K. Fried, C. Susini, and P. Freychet. 1979. Mechanism of insulin resistance in adipocytes of rats fed a high-fat diet. J. Lipid Res. 20:8-16.

18. Dole, V. P., and H. Meinertz. 1960. Microdetermination of long-chain fatty acids in plasma and tissues. J. Biol. Chem. 235:25952599.

19. Susini, C., and M. Lavau. 1978. In vitro and in vivo responsiveness of muscle and adipose tissue to insulin in rats rendered obese by a high-fat diet. Diabetes. 27:114-120.

20. Crandall, D. L., S. K. Fried, A. A. Francendese, M. Nickel, and M. DiGirolamo. 1983. Lactate release from isolated rat adipocytes: 
influence of cell size, glucose concentration, insulin and epinephrine. Horm. Metab. Res. 15:326-329.

21. Gammeltoft, S., and J. Gliemann. 1973. Binding and degradation of ${ }^{125}$ I-labelled insulin by isolated rat fat cells. Biochim. Biophys. Acta. 320:16-32.

22. Gliemann, J., W. D. Rees, and J. Foley. 1984. The fate of labelled glucose molecules in the rat adipocyte. Dependence on glucose concentration. Biochim. Biophys. Acta. 804:68-76.

23. Martin, D. B., M. G. Horning, and P. R. Vagelos. 1961. Fatty acid synthesis in adipose tissue. I. Purification and properties of a long chain fatty acid-synthesizing system. J. Biol. Chem. 236:663-668.

24. Olefsky, J. M., and M. Kao. 1982. Surface binding and rates of internalization of ${ }^{125} \mathrm{I}$ insulin in adipocytes and IM-9 lymphocytes. J. Biol. Chem. 257:8667-8673.

25. Sonne, O., and I. Simpson. 1984. Internalization of insulin and its receptor in the isolated rat adipose cell. Time-course and insulin concentration dependency. Biochim. Biophys. Acta. 804:404-413.

26. Scatchard, G. 1949. The attraction of proteins for small molecules and ions. Am. N.Y. Acad. Sci. 51:660-672.

27. Kahn, C. R., P. Freychet, J. Roth, and D. M. Neville. 1974. Quantitative aspects of the insulin-receptor interaction in liver plasma membranes. J. Biol. Chem. 249:2249-2257.

28. De Meyts, P., J. Roth, D. M. Neville, J. R. Gavin, and M. A. Lesniak. 1973. Insulin interactions with its receptors: experimental evidence for negative cooperativity. Biochem. Biophys. Res. Commun. 55:154-161.

29. Guynn, R. W., D. Veloso, and R. I. Veech. 1972. The concentration of malonyl-coenzyme $\mathrm{A}$ and the control of fatty acid synthesis in vivo. J. Biol. Chem. 247:7325-7331.

30. Cushman, S. W., and L. J. Wardzala. 1980. Potential mechanism of insulin action on glucose transport in the isolated rat adipose cell. Apparent translocation of intracellular transport systems to the plasma membrane. J. Biol. Chem. 255:4758-4762.

31. Suzuki, K., and T. Kono. 1980. Evidence that insulin causes translocation of glucose transport activity to the plasma membrane from an intracellular storage site. Proc. Natl. Acad. Sci. USA. 77:25422545.

32. Cushman, S. W., L. J. Wardzala, P. J. Hissin, E. Karnieli, I. A. Simpson, and L. B. Salans. 1983. Mechanism of insulin resistant glucose transport in the isolated rat adipose cell. In The Adipocyte and Obesity: Cellular and Molecular Mechanism. A. Angel, C. H.
Hollenberg, and D. A. K. Roncari, editors. Raven Press, NY. 905911.

33. Guerre-Millo, M., M. Lavau, J. S. Horne, and L. J. Wardzala. 1985. Proposed mechanism for increased insulin-mediated glucose transport in adipose cells from young obese Zucker rats: large intracellular pool of glucose transporters. J. Biol. Chem. 260:2197-2201.

34. Foley, J. E., S. W. Cushman, and L. B. Salans. 1980. Intracellular glucose concentration in small and large adipose cells. Am. J. Physiol. 238:E180-E185.

35. Salans, L. B., J. E. Foley, L. J. Wardzala, and S. W. Cushman. 1981. Effects of dietary composition of glucose metabolism in rat adipose cells. Am. J. Physiol. 240:E175-E183.

36. Richardson, D. K., and M. P. Czech. 1978. Primary role of decreased fatty acid synthesis in the insulin resistance of large rat adipocytes. Am. J. Physiol. 234:E182-E189.

37. Fried, S. K., M. Lavau, and F. X. Pi-Sunyer. 1981. Role of fatty acid synthesis in the control of insulin-stimulated glucose utilization by rat adipocytes. J. Lipid Res. 22:753-762.

38. Volpe, J. J., and P. R. Vagelos. 1976. Mechanisms and regulation of biosynthesis of saturated fatty acids. Physiol. Rev. 56: 339-417.

39. Wade, G. N., and J. M. Gray. 1979. Gonadal effects on food intake and adiposity: a metabolic hypothesis. Physiol. Behav. 22:583593.

40. Flint, D. E., R. A. Clegg, and R. G. Vernon. 1983. Adipose tissue metabolism during early pregnancy in the rat: temporal relationships of changes in the metabolic activity, number of insulin receptors, and serum hormone concentrations. Arch. Biochem. Biophys. 224 677-681.

41. Pedersen, O., E. Hjøllund, and H. O. Lindskov. 1982. Insulin binding and action on fat cells from young healthy females and males. Am. J. Physiol. 243:E158-E167.

42. Foley, J., A. J. Kashiwagi, H. Chang, T. P. Hueckstaedt, S. Lillioja, M. A. Verso, and G. Reaven. 1984. Sex-differences in insulinstimulated glucose transport in rat and human adipocytes. Am. J. Physiol. 246:E211-E215.

43. Sclafani, A., and A. N. Gorman. 1977. Effects of age, sex and prior body weight on the development of dietary obesity in adult rats. Physiol. Behav. 18:1021-1026.

44. Jen, K. L. C., M. R. C. Greenwood, and J. A. Brasel. 1981. Sex differences in the effects of high-fat feeding on behavior and carcass composition. Physiol. Behav. 27:161-166. 